\title{
Analysis of Intellectual Property Rights Guidelines for Crowdsourced Software Engineering Platforms
}

\author{
Badariah Solemon $^{1}$, Hani Al-Bloush ${ }^{2}$ \\ ${ }^{1}$ Institute of Energy Infrastructure, Universiti Tenaga Nasional, Jalan IKRAM-UNITEN, Kajang 43000, Selangor, \\ Malaysia, badariah@uniten.edu.my \\ ${ }^{2}$ College of Graduate Studies, Universiti Tenaga Nasional, Jalan IKRAM-UNITEN, Kajang 43000, Selangor, \\ Malaysia, hanibarjes@yahoo.com
}

\begin{abstract}
Crowdsourced Software Engineering (CSE) is as a powerful tool to generate better software products or services with high quality, better reliability, and flexibility at a lower cost and shorter time. The Literature review performed shows there has been no investigation conducted on how existing crowdsourcing platforms supporting CSE activities deal with the rights of intellectual property (IP) produced by the crowd for the crowdsourcer. Therefore, we researched to develop new IP rights (IPR) guideline for such crowdsourcing platforms. Before developing the new guideline, we identified and analyzed four existing IPR guidelines. The guidelines are 1) Guideline for Treatment of Intellectual Property Rights in Information and Communication Technology (ICT) Contracts, 2) Government IP Policy and Best Practice Guideline, 3) IP Guideline for Custom Software Development Contracts, and 4) Implementation Guide Policy on Title to IP Arising Under Crown Procurement Contracts. The results of the analyses reveal two components and several sub-components essential to set straight the structure of the new IPR guideline. The two components are Introduction and Guideline. The subcomponents are Background, Purpose, Scope, Definition, and Statement of Policy for the Introduction component and Description, Circumstances, Anticipates, and Benefits for the Guideline component. This new IPR guideline is vitalto provide the stakeholders of CSE activities with the direction to a more logical decision-making sequence related to CSE platforms.
\end{abstract}

Key words: intellectual property rights (IPR), guideline, crowdsourced software engineering (CSE), protection, ownership

\section{INTRODUCTION}

The crowdsourcing approach introduced by Howe in 2006 has inspiredthecreation of a new landscape for software engineering activities through the exploitation of collective intelligence in an online, distributed problem-solving and production environment[1-3].
As stated in [3], "Software engineering no longer takes place in small, isolated groups of developers, but increasingly takes place in organizations and communities involving many people." Various terms have surfaced to indicate this new landscape for software engineering activities, and among them is 'Crowdsourced Software Engineering' (CSE)[4]. CSE can be easily distinguishable from an inhouse development based on the ways of working of the former through open call format that allows anyone to participate.

Since CSE has unique features, the software industry takes the opportunity to obtain the benefits of these features to generate better software products or services with high quality, better reliability, and flexibility at a lower cost and shorter time $[3,4,6]$. For instance, TopCoder's crowdsourcing development holds the ability to provide crowdsourcer's request at a lower cost with less time and less defect rate [7]. These promising benefits reported mainlyby TopCoder are cost reductions of $30 \%-80 \%$ or 5 to 8 times decrease in defect rate compared with in-house software development practices as reported in[8].

Crowdsourcing software engineering activities may introduce a potential emergence of an Intellectual Property (IP) concern since software development "is an intellectual activity and is dominated by often-neglected human factors (called human aspects in software engineering research). Among the many skills required for software development, developers must possess high analytical problem-solving skills and creativity for the software construction process." [9].

The Cambridge Dictionary defined IP as “someone's idea, invention, creation, etcetera, that can be protected by law from being copied by someone else." Software engineering tasks completed through CSE platforms may have IP concern as these crowdsourcing tasks are contrary to in-house development through the normal recruitment process.

In the context of management and control of intellectual property rights (IPR), generally, the employer will own the intellectual property (IP) generated by its employees while in their employment. In the case of CSE, the ownership is 
ambiguous because of the involvement of three different stakeholders (crowd, crowdsourcer, and platform).

Thus the default IPR and commitments in crowdsourcing situations are contrary to that of in-house employment. While existing literature emphasizes IP concerns in general, together with its associated risks and strategies on how to balance the rights of the crowdsourcer and the crowd, there has been no investigation conducted on how existing crowdsourcing platforms supporting CSE activities deal with IPR. Therefore, we conducted research to develop a new IPR guideline for crowdsourcing platforms for supporting CSE activities to guide crowdsourcing platforms to strike a balance between crowdsourcer protection and crowd participation maximization to increase crowdsourcing success.

Before developing the new guideline, we identified and analyzed four existing general IPR guidelines, as discussed in Section IV of this paper. Section II presents a literature review of CSE activities and IPR concern, and Section III briefly explain the methodology used to develop the new IPR guideline for crowdsourcing platforms to support CSE activities. Section V concludes the findings of the analysis.

\section{MATERIALS AND METHODS}

This section begins with the review of literature related to the roles of three crowdsourcing actors: crowdsourcer, platform, and the crowd. Then it moves on to theassessment of IPR concerns and IPR protections in CSE activities and methodology adopted in building the IPR guideline for crowdsourcing platforms.

\section{A. Roles of Actors in a Crowdsourcing Process}

Based on Howe's definition, the three types of actors who play various roles in the crowdsourcing processare crowdsourcer, crowd, and platform.

In the case of CSE, the crowdsourcer could be an organization or individual who seeks online assistance to get software engineering tasks done, the crowd are often individuals who take part in developing software engineering tasks, and the platform provides an online infrastructure that acts as a mediator between the crowdsourcer and the crowd to accomplish the CSE tasks. Figure 1 depicts the roles of eachactor need to act upon, and the interactions that exist between the actors.

Typically, crowdsourcers and crowd on these crowdsourcing platforms are unknown to each other and may not abide by similar rules and the roles of regulatory for accomplishing the tasks [10].

Therefore, crowdsourcing platforms play a vital role in facilitating the interaction between crowd and crowdsourcers. This interaction happens through a series of mechanisms involving enrolment, authentication, crowdsourcer task broadcast, task assignment, assistance, crowd skill declaration, time negotiation, price negotiation, result submission, result verification, coordinate crowd, supervise crowd, and feedback loops.

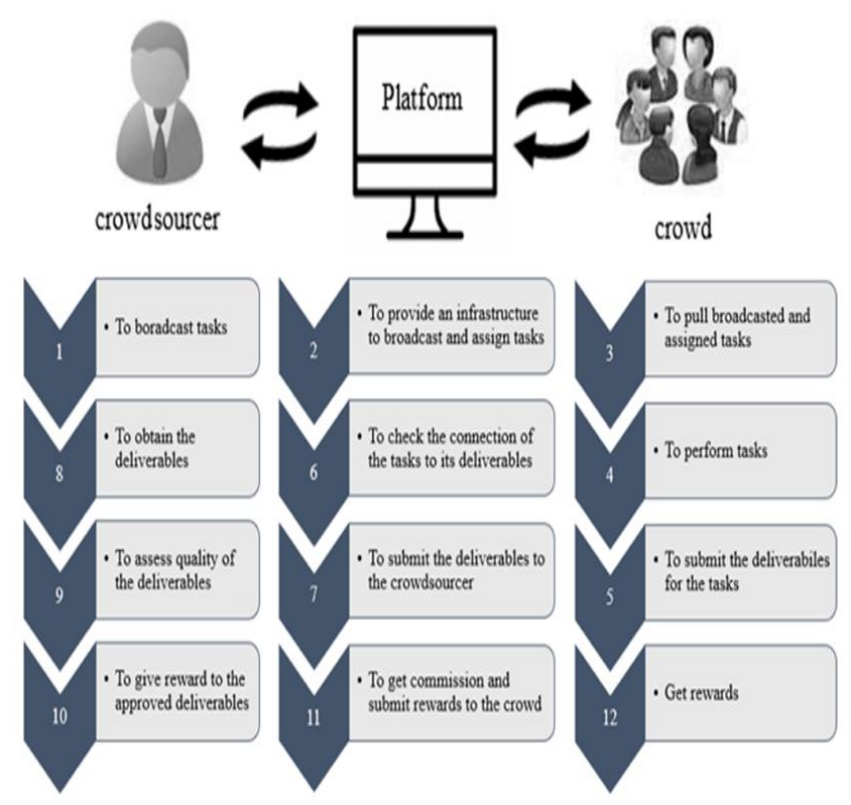

Figure 1: Crowdsourcing actors and roles

\section{B. CSE Activities and IPR Concern}

Any software activities can be crowdsourced [12], including software analysis, software design, software coding, software testing, software verification software evolution, and software maintenance. These CSE activities are implemented in the form of assigned tasks through online open call involving various CSE stakeholders, who play different roles and interact with each other to complete CSE activities. Each task may involve different stakeholders according to the specialized knowledge of the assigned task, which requires different skills, tools, and techniques to accomplish the task [4, 13].CSE tasks include requirements related tasks such as software idea generation, capturing user requirements, requirements categorization, converting user requirements into software feature, and representing software requirements into a UML diagram. Other CSE tasks include user interface design, algorithm writing, software design, receiving design feedbacks and critiques, writing codes for the design, reviewing the codes, functional test, performance test, usability test, localization test, GUI testing, code testing, beta testing, problem mitigation, general evaluation, test generation, non-expert verification, software adaptation, software documentation, and software localization.

A range of previous studies has considered potential IPR as a source of concern on the assigned CSE tasks. Of these 
studies [3, 4,14-18], stated that CSE tasks require intellectual creativity and may raise a concern about knowledge and IPR. Most of these studies did not clearly express specific IP challenges. However, Ford, Robert, Brendan, and Michael in[19] briefly stated that the concern is the IP ownership and focused on who would own the actual IP created by the crowd.De Beer et al. in [15] confirmed not only the IP ownership concern but also the existence of the associated risks of the content submitted by the crowd.

\section{Types of IPR Protection in CSE Activities}

The field of software engineering is considered a field requiring creativity encompassing nearly all of its aspects like requirements specifications, design documents, and source code represent [20]. Liu, Feng, Li, Jing, and Yang in [21] commented that "While culture being the software controlling the human mind, computer software development becomes one of the most creative activities that human undertakes since the civilization began." In this regard, it is not surprising that software protection under IPR is critical to the software industry [22]. Moreover, Afegbua in [23] stated that: "IP rights are at the foundation of the software industry, the term refers to a range of intangible rights of ownership in an asset such as a software program." IPRs are therefore considered in itself an asset, a slice of the overall ownership pie. With its relevance, there is a need to manage the protection of IPs, and this is the rationale behind the available provisions in the law providing different types in protecting ownership rights. The six types of IPRs protections that are relevant to software engineering activities are namely: copyrights, patents, trade secrets, trademarks, industrial design and database rights [24].

\section{Methodology}

Our research proposes a concrete guideline encompassing the integrated CSE activities detailing recommendations to the crowdsourcing platforms on the proper management and control of IPR shall provide a definite direction to improve their process in software task broadcasting and assigning mechanisms. The input to build and define the recommendations in the guideline begins with the review of literature and document analysis. Then, theresearch continues with the development of the guideline specific for IPR management and control.

In order to build the IPR guideline for crowdsourcing platforms, we analyzed legal documents of existing crowdsourcing platforms and reviewed existing IPR guidelines. Then, we abstracted the standard rules or instructions from these guidelines.Later, we identified the circumstances revolving around the value of the Foreground (newly created IP) to enable the creation of the decisionmaking process regarding the Foreground ownership and licensing options. As part of the identification of sound practices, we also reviewed available online contractual agreements to be able to conclude which form is superior to deliver an enforceable agreement ensuring the delivery of transparency and fairness between entities. In order to ensure a logical presentation of the recommendations, we synthesize the structure and component of the guidelines.

The development of consolidated evaluation criteria follows this as the lack of specific IPR guideline was identified through two widely used appraisal criteria for practice guidelines. Then, the process continues to identify the domains essential to ensure the quality of the IPR guideline, and the items to provide a unique dimension for the domain. The proposed guideline when through two rounds of evaluation and refinement using the consolidated evaluation criteria. However, due to limited space, this paper focuses

only on presenting the results of the analysis of existing IPR guidelines that form the basis of the new guideline for crowdsourcing platforms supporting CSE activities.

\section{Results and discussion}

\section{A. Overview of the Existing Guidelines}

The four guidelines analyzed in this study are 1) Guideline for Treatment of Intellectual Property Rights in Information and Communication Technology (ICT) Contracts (G1)[25], 2) Government IP Policy and Best Practice Guideline (G2) [26], 3) IP Guideline for Custom Software Development Contracts (G3) [27], and 4) Implementation Guide Policy on Title to IP Arising Under Crown Procurement Contracts (G4) [28]. These guidelines set out approach (G1), framework (G3), and policy (G4) to make appropriate decisions on Foreground arising from general contract deliverables between entities. Slightly focused guideline G2 provides best practices guidelines to assist Government Agencies to make appropriate decisions on Foreground arising from contract deliverables between entities.Table I presents a summary of four guidelines and their necessaryinformation, which streamlined the IPR practices of different organizations according to their activities, labelled from G1 to G4.

As stated in [29], guideline documents provide an appropriate and reliable source for understanding the IP sound practices required in various circumstances. The practices revolve around the decision-making process to identify IP rights ownership and licensing (i.e., commercialization, utilization, and modification). The decision-making process highly depends on the provisions regarding the complexities surrounding the identification of the first owner of a Foreground and the variety of the probable circumstances [30]. 
Badariah Solemon et al., International Journal of Emerging Trends in Engineering Research, 8(10), October 2020, 6675 - 6683

Table 1: List of existing IP guidelines and related information

\begin{tabular}{|c|c|c|c|c|c|c|}
\hline ID & Name & Category & Origin & Authors or Publisher & Year & Source \\
\hline$\overline{\text { G1 }}$ & $\begin{array}{l}\text { Guideline for Treatment of } \\
\text { Intellectual Property Rights in } \\
\text { Information and Communication } \\
\text { Technology (ICT) Contracts }\end{array}$ & ICT & $\begin{array}{l}\text { New } \\
\text { Zealand }\end{array}$ & $\begin{array}{l}\text { New Zealand State } \\
\text { Services Commission }\end{array}$ & 2008 & {$[25]$} \\
\hline $\mathrm{G} 2$ & $\begin{array}{l}\text { Government IP Policy and Best } \\
\text { Practice Guideline }\end{array}$ & Generic & Australia & $\begin{array}{l}\text { Department of Industry } \\
\text { and Resources in } \\
\text { conjunction with the } \\
\text { Government IP Policy } \\
\text { Council }\end{array}$ & 2003 & {$[26]$} \\
\hline G3 & $\begin{array}{l}\text { IP Guideline for Custom Software } \\
\text { Development Contracts }\end{array}$ & $\begin{array}{l}\text { Software } \\
\text { Developme } \\
\text { nt }\end{array}$ & Canada & $\begin{array}{l}\text { Department of Highways } \\
\text { and Public Works } \\
\text { Information \& } \\
\text { Communications } \\
\text { Technology }\end{array}$ & 2005 & [27] \\
\hline G4 & $\begin{array}{l}\text { Implementation Guide Policy on } \\
\text { Title to IP Arising Under Crown } \\
\text { Procurement Contracts }\end{array}$ & Generic & Canada & $\begin{array}{l}\text { Ministry of Industry, } \\
\text { Government of Canada }\end{array}$ & 2015 & [28] \\
\hline
\end{tabular}

Parr in [31] substantiates the view regarding the issues in his book concerning licensing, where he emphasized theneed foridentification of the first owner of the Foreground to ensure proper exploitation.

The IP anticipated in the deliverables of software engineering activities includes all application software, database software, web software, documents, materials, recorded information of other assets, and products of any kind. Out of the four guidelines, only one guideline suits for software engineering activities (G3). Two are of the generic category (G2 and G4), and another one is for the general Information and Communication Technology (ICT) category (G1).

\section{B. Foreground Ownership and Licensing Position}

A review performed on these four guidelines revealed the differences with regards to their scope of applications. However, similarities observed between each other arethe provision of standard rules or instructions in making appropriate decisions, whether regardingthe Foreground ownership and licensing position between entities (clients and suppliers). The provision is consistent with the Oxford dictionary in defining guideline as “... set of rules or instructions that are given by an official organization telling you how to do something, especially something difficult".

There are three primary positions for the IPR ownership and licensing provided by these guidelines, labelled from P1 to P3, summarized in Fig. 2. Primarily, these guidelines seek to provide clarity anddirectionon all the probable circumstances, in which clientsmustbegrantedownership rightonany Foreground arising from the deliverables. The direction comes to the context based on the precaution needed to be taken by the client before getting into an agreement as stated in [32], which suggestedthatclients are supposed to provide the intention to own the Foreground explicitly. The precautionhelps avoid the settlement with a silent agreement wherein best case scenario can only grant the license to the client. Secured IP ownership is a must before any IP execution as failure to do so may disrupt the attainment of the desired objective, and this ensures the right of the client on the developed Foreground in order to avoid any inappropriate exploitations [33].

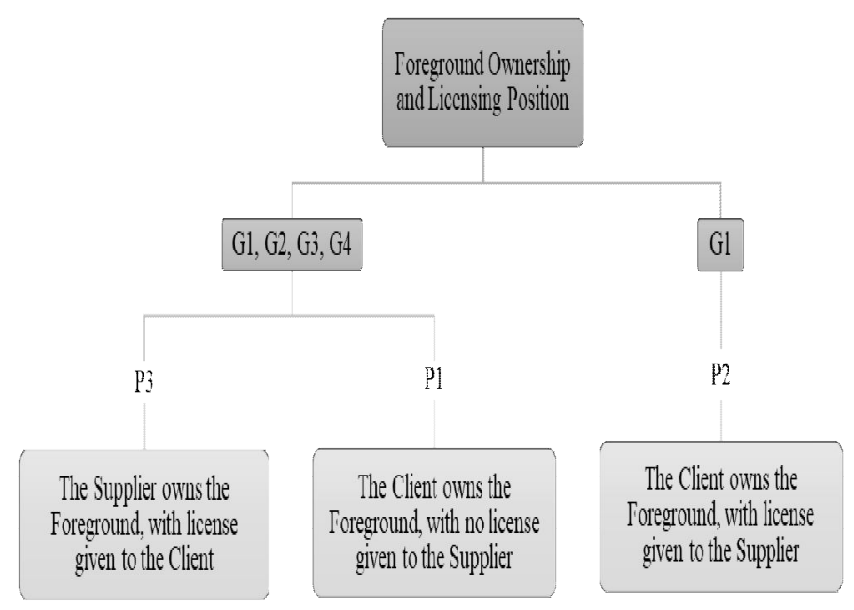

Figure 2: Summary of Foreground ownership and licensing positions

Based on Fig. 2, all of the guidelines provide an option for the client to own the Foreground without granting the license to the supplier (P1). Although $\mathrm{G} 1$ provided an ownershipcircumstance wherein even if the client is to own the Foreground, the supplier owns the license for exploitation for the satisfaction of both parties (P2). These guidelines also specified cases wherein the client might 
Badariah Solemon et al., International Journal of Emerging Trends in Engineering Research, 8(10), October 2020, 6675 - 6683

consider not acquiring the ownership right provided that it does not affect the desired purpose (P3). Therefore, in theseparticular instances, the supplier has the opportunity to own the Foreground with a pre-requisite that the client holds the exploitation license, which includes any third-party affiliation.Burden in [34] commented on that as "...if a client is not going to own the IP rights but is concerned about its potential loss of competitive advantage if the supplier can market the new materials elsewhere freely, a provision can be inserted to prohibit the supplier utilizing the materials with the client's competitors (either at all or for a stated period)".

\section{IPR Ownership and Licensing Strategy}

Based on the analysis of the four guidelines, there are three proposed positions on the ownership and licensing strategy after taking into account individual circumstances based on the necessity of the Foreground. These circumstances revolve in general around the value of the newly arising IP or Foreground and the pre-existing IP or Background, which is provided by both client and supplier and primarily influence the decision-making process presented in each of the Foreground ownership and licensing position offered by these guidelines. After this, the circumstances presented in each of the guidelines were categorized based on the similarities and were linked upon the rationale supporting the position an entity must undertake. For instance, G1 stated that IPR applicable to a critical system supports the position whereby the client should own the IP rights [35]. Taking another example in $\mathrm{G} 2$, it states that statutes, regulations, or prior obligations of the client to a third party or parties preclude supplier ownership of the Foreground [36]. This circumstance was grouped with the circumstance presented in G1 as both support the same position. The categorization, in turn, simplifies the decision-making process by summarizing which circumstances support each of the positions supported by a valid rationale. In summary, 13 circumstances are supporting this three ownership and licensing positions, as presented in [11].

As the nature of circumstances enables the identification of the appropriate position to be undertaken, this finalized position will limit the scope of necessary provisions required in the contractual agreement. The position is a legally enforceable agreement binding the two entities whereby the acceptance signifies absolute compliance and any noncompliance.In alignment with the goal of this study, the electronic version of contractual agreement where users can access and signify to the provisions of the legal agreement online is analyzed further.Legal agreements are in the form of a contract in which involved parties to act in full compliance with the contract. The formation of online contractual agreements prominently used in the online marketplace (i.e., website) is clickwrap and browsewrap. Fig. 3 shows an example of aclickwrap wherethe user gets to read the terms and conditions of use of a website (on a page, or in a scroll box), and clicking on a button 'I accept' or any other language with similar meaningshall signify undertaking the desired activity.On the other hand, a browsewrapenables websites to present terms and conditions, which is commonly through accessing a hyperlink not requiring any active expression of consent before undertaking any activities. As reported in [37], browsewrap agreement will be typically placed and linked at the bottom of the website.Thus, clicking the 'Terms of Service' link shall present the legal agreement terms, as seen in Fig. 4.

Terms \& Conditions

The website is operated by Through the site, the terms "we", "us" and "our" refer to offers this website, including all information, tools and services available from this site to you, the user, conditioned upon your acceptance of all terms, conditions, policies and notices stated here.

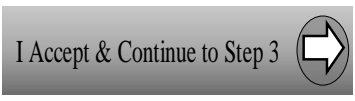

Figure 3: Sample of clickwrap online agreement

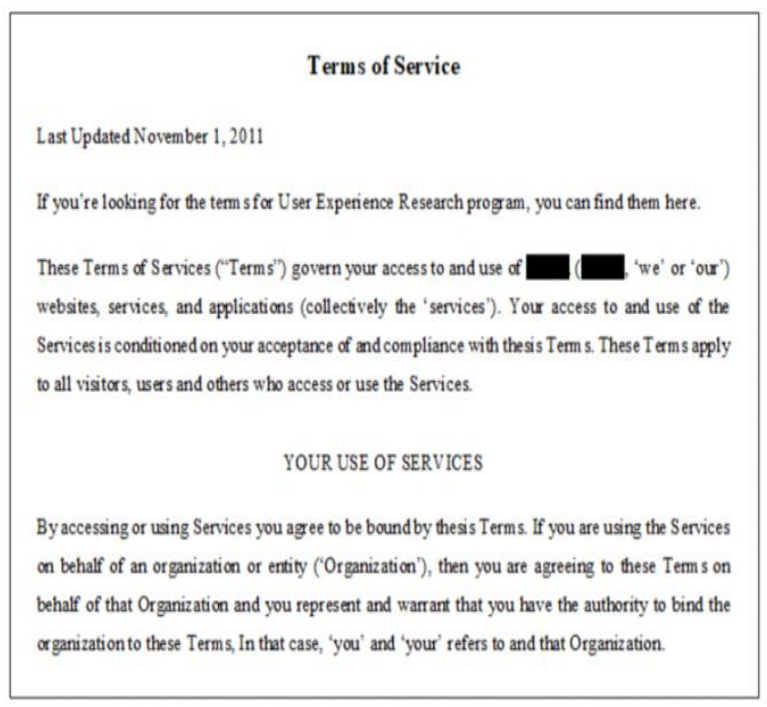

Figure 4: Sample of browsewrap online agreement

Although the approach protects users using clickwrap and browsewrapagreements, it does not dilute the existence of some legal issues. Because of browsewrap nature of not drawing attention to the actual agreements and terms, the crowdsourcing platforms may resort in hiding the provisions of the terms and, /or deflecting attention from the terms (i.e., use of graphics and small font sizes and use of complex searches through screens to find the terms) [38].

According to Marotta-Wurgler, in [39], responsible users "...are likely to read and digest terms in a medium conducive to speed, instant gratification, and manipulation." 
Badariah Solemon et al., International Journal of Emerging Trends in Engineering Research, 8(10), October 2020, 6675 - 6683

However, it is a typicalcase that the users exhibit reluctance to read the terms and appeal to unfair terms even if these are properly presented. Somehow, the user cannot argue that a contract does not exist just because the user did not read it before proceeding. Therefore, even if clickwrap is similar to the traditional paper transactions, whichrequires solicitation of consent, it is at times an overstatement if the user didnot recognize their responsibility of reading and understanding the terms [40-41].

\section{Structure and Components of the Guidelines}

Table 4 presents asummary of the review of the guidelines selected in this study based on their structure and components. The structure of each guideline presents the design of the documents concerning its function and has two domains, which firstly introduces the source of the IP and consequently presenting the IP sound practices in guiding the decision-making process. The review findings show that the structure of the guideline is generally similar among the guidelines. The finding is consistent with [39] in their recommendation that "... a guideline can be structured either as collections of decisions that are to be applied in specific situations or as processes that specify activities that take place over time".Peleg et al. in [42] affirmedthat the overall flow of the guideline structure starts from the integrated description of the decision-making process and activity specification and ends with a description of the process of expression that allows for sequencing and repetition in decisions and activities.

Table II shows the two main components of the guidelines, Introductionto provides the general components of the guideline, and Guidelinesto present sound IP practices. The Background component of G1, G2 and G3 provides the context of the creation of the documents. Despite G4 not having a separate component to present the Background of the guideline, it was briefly explained in another component which is Purpose. Each of the guideline presents the rationale on the creation of the guideline under three headings. The headings are:1)Purpose to provide the areas where the guideline is applicable to under, 2)Scopeto give clarity, and 3) Definitions to align the interpretation of terms that are being used throughout the guideline. On the other hand, G1, G2, and G3 havea component named Statement of Policy. This component provides the underlying philosophy of the guideline to be related to the agencies' and or parties' mission and values, a component tailored to the entities involved in the guidelines.

With regards to the review of the components of the specific IP practices, the guidelines were presented in a rational approach by initially introducing the description of the IP ownership position alongside with the enumeration of its applicable circumstances followed by the benefits for the use of the aforementioned option. As compared to the other guidelines in which clearly defined the pre-condition or Anticipates of the position, G2 included the allocation processes in determining the ownership. Besides, G2 presented sound practices only by enumeration in contrast with G1, G3, and G4, whereby sound practices were summarized using a pre-determined decision flow process.

Based on the review of the components, the essential guideline's components are Introduction and Guideline. The Introductioncomponent consists of Background to presents the context in the creation of the guideline, Purpose on what the guideline is for, Scope topresent the extent to which the guideline is relevant,Definitions to provide definite meaning into the terms usedinthe guideline, and Statement of Policyinorder to achieve the purpose of the guideline. As for the Guideline component, the following sub-components are proposed: 1)Description to clearly describe the IPR ownership positions including the scope of the management of the IP, 2)Circumstances to present the situations where the IP ownership position is applicable and not applicable, 3) Anticipates of the IP ownership position to describe the precondition of the IP either be Foreground or Background, and 4)Benefits to provide a line of sight in between the position and the objectives of the parties involved.

Table 2 : Structure and Components of Existing IP guidelines

\begin{tabular}{|l|l|l|l|l|l|}
\hline & G1 & G2 & G3 & G4 \\
\hline $\begin{array}{l}\text { Structure of the } \\
\text { guidelines }\end{array}$ & & $\begin{array}{l}\text { Foreground in ICT Contract } \\
\text { Deliverables } \rightarrow \text { Sound Practices } \\
\text { Guidelines }\end{array}$ & $\begin{array}{l}\text { Foreground in } \\
\text { Government } \\
\text { Contract (GC) } \\
\text { Deliverables } \rightarrow \\
\text { Sound Practices } \\
\text { Guidelines }\end{array}$ & $\begin{array}{l}\text { Foreground in } \\
\text { Customer Software } \\
\text { Development (CSD) } \\
\text { Contracts } \\
\text { Deliverables } \rightarrow \\
\text { Sound Practices } \\
\text { Guidelines }\end{array}$ & $\begin{array}{l}\text { Foreground arising in } \\
\text { Crown Procurement } \\
\text { Contracts (CPC) } \\
\text { Deliverables } \rightarrow \text { Sound } \\
\text { Practices Guidelines }\end{array}$ \\
\hline $\begin{array}{l}\text { Specific } \\
\text { practices }\end{array}$ & & $\begin{array}{l}\text { Right to Foreground in ICT } \\
\text { contract Deliverables: }\end{array}$ & $\begin{array}{l}\bullet \text { Right to } \\
\text { Foreground in GC } \\
\text { Deliverables: }\end{array}$ & $\begin{array}{l}\text { Right to } \\
\text { Foreground in CSD } \\
\text { contract } \\
\text { Deliverables: }\end{array}$ & $\begin{array}{l}\text { Foreground in CPC } \\
\text { Deliverables: }\end{array}$ \\
\hline
\end{tabular}


Badariah Solemon et al., International Journal of Emerging Trends in Engineering Research, 8(10), October 2020, 6675 - 6683

\begin{tabular}{|c|c|c|c|c|c|}
\hline & & $\begin{array}{l}\text { Ownership and } \\
\text { Commercialization }\end{array}$ & $\begin{array}{c}\text { Ownership and } \\
\text { Commercialization }\end{array}$ & $\begin{array}{l}\text { Granting and } \\
\text { Retention of } \\
\text { Foreground } \\
\text { Ownership }\end{array}$ & $\begin{array}{l}\text { Ownership and } \\
\text { Exploitation }\end{array}$ \\
\hline $\begin{array}{l}\text { Sound } \\
\text { practices } \\
\text { guidelines for } \\
\text { implementation }\end{array}$ & & $\begin{array}{l}\text { - Set out an approach to } \\
\text { make appropriate decisions on } \\
\text { Foreground arising from } \\
\text { contract deliverables between } \\
\text { entities }\end{array}$ & $\begin{array}{l}\text { - Best practices } \\
\text { guidelines to assist } \\
\text { Government } \\
\text { Agencies to make } \\
\text { appropriate } \\
\text { decisions on } \\
\text { Foreground arising } \\
\text { from contract } \\
\text { deliverables between } \\
\text { entities }\end{array}$ & $\begin{array}{l}\text { - Provides a } \\
\text { framework to make } \\
\text { appropriate } \\
\text { decisions on } \\
\text { Foreground arising } \\
\text { from contract } \\
\text { deliverables between } \\
\text { entities }\end{array}$ & $\begin{array}{l}\text { - Set out a policy to } \\
\text { make appropriate } \\
\text { decisions on } \\
\text { Foreground arising } \\
\text { from contract } \\
\text { deliverables between } \\
\text { entities }\end{array}$ \\
\hline $\begin{array}{l}\text { Component of } \\
\text { the guidelines }\end{array}$ & 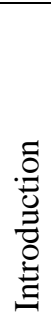 & $\begin{array}{l}\text { - } \text { Definitions } \\
\text { - Purpose } \\
\text { - Scope } \\
\text { - Background } \\
\text { - Statement of Policy }\end{array}$ & $\begin{array}{l}\text { - } \text { Background } \\
\text { - Purpose } \\
\text { - Scope } \\
\text { - Definitions } \\
\text { - Statement of } \\
\text { Policy }\end{array}$ & $\begin{array}{l}\text { - } \text { Background } \\
\text { - Statement of } \\
\text { Policy } \\
\text { - } \quad \text { Definitions } \\
\text { - Purpose } \\
\text { - Scope }\end{array}$ & $\begin{array}{ll}\text { - } & \text { Purpose } \\
\text { - } & \text { Definitions } \\
\text { - Scope }\end{array}$ \\
\hline & $\frac{\mathscr{0}}{: 0}$ & $\begin{array}{l}\text { - } \text { Description } \\
\text { - Circumstances } \\
\text { - Anticipates } \\
\text { - Benefits } \\
\text { - Practical Examples }\end{array}$ & $\begin{array}{l}\text { - } \quad \text { Description } \\
\text { - Default option } \\
\text { - Exceptions } \\
\text { Circumstances } \\
\text { - Anticipates } \\
\text { - Benefits }\end{array}$ & $\begin{array}{l}\text { - } \quad \text { Principles } \\
\text { - } \quad \text { Exceptions } \\
\text { Circumstances } \\
\text { - Anticipates } \\
\text { - } \quad \text { Benefits }\end{array}$ & $\begin{array}{ll}\text { - } & \text { Description } \\
\text { - } & \text { Steps } \\
\text { - } & \text { Circumstances } \\
\text { - Anticipates }\end{array}$ \\
\hline
\end{tabular}

\section{CONCLUSION}

This paper establishes the importance of IP rights management by providing a comprehensive review of the sound practices in four existing guidelines. The review revealsthree primary positions for the IP rights ownership and licensing provided by these guidelines and the identification of the thirteen circumstances supporting these three positions, which evolve in general around the value of the newly arising IP or Foreground and the pre-existing IP or Background. Additionally, this finalized position shall enable the identification of necessary provisions required in a contractual agreement in which in an online marketplace takes form as clickwrap and browsewrap.In this paper, the analysis of four existing IPR guidelines named as G1, G2, G3, and G4resulted in the identification of components and sub-components for the proposed new IPR guideline for crowdsourcing platforms to support CSE activities. This paper begins with the literature review of CSE activities and IPR concerns in Section II, followed by brief explanation of the methodology adopted to develop the new IPR guideline. The identification of those components isessential to set straight the structure of the new IPR guideline so that it can provide end-user with the direction to a more logical decision-making sequence.

The four guidelines have been evaluated based on consolidated criteria. The criteria were developed for the appraisal of the quality of guidelines specifically for the management of IPR. The criteria include scope \& purpose, stakeholder involvement, the rigour of development, clarity of presentation, update date, and applicability. The evaluation was conducted not for the purpose of verifying the validity of these guidelines as these guidelines are valid and are currently active. Instead, it is a confirmatory exercise for the presence and absence of the criteria and how these 
Badariah Solemon et al., International Journal of Emerging Trends in Engineering Research, 8(10), October 2020, 6675 - 6683

influence the fulfilment of the guideline's purpose. The evaluation results of the four guidelines and the detailed explanation of the new guideline for CSE platforms are detailed in [11].

\section{ACKNOWLEDGEMENT}

We would like to thank UNITEN and Innovation \& Research Management Center (iRMC) for funding this research publication through project code: 10436494/B/201906.

\section{REFERENCES}

[1] C. Brabham, "Crowdsourcing as a model for problem solving: An introduction and cases", Convergence, 14(1), 75-90, 2008.

[2] J. Howe, "The rise of crowdsourcing", Wired Magazine, 14(6), 1-4, 2006.

[3] K. Mao, L. Capra, M. Harman, and Y. Jia, "A Survey of the Use of Crowdsourcing in Software Engineering",Journal of Systems and Software, 126, 5784, 2017.

[4] K.-J.Stol andB.Fitzgerald, "Two's company, three's a crowd: a case study of crowdsourcing software development", Proceedings of the 36th International Conference on Software Engineering, 2014.

[5] (Siyal \& Franch, 2018

[6] Suganthy and T. Chithralekha, "Application of crowdsourcing in software development", International Conference on the Recent Trends in Information Technology (ICRTIT), 2016.

[7] N. Archak, "Money, glory and cheap talk: analyzing strategic behavior of contestants in simultaneous crowdsourcing contests on TopCoder.com",Proceedings of the 19th international conference on World wide web, 2010.

[8] K. R. Lakhani, "Managing communities and contests to innovate with crowds". Revolutionizing Innovation: Users, Communities, and Open Innovation, 109, 2016.

[9] Graziotin, X. Wang, andP. Abrahamsson, "Happy software developers solve problems better: psychological measurements in empirical software engineering", PeerJ, 2, e289, 2014.

[10]D. R. Saunders, P. J. Bex, andR. L. Woods, "Crowdsourcing a normative natural language dataset: a comparison of Amazon Mechanical Turk and in-lab data collection",Journal of medical Internet research, 15(5), e100, 2013.

[11] H. Al-Bloush, Safeguarding Intellectual Property Rights on Crowdsourcing Platforms - A New Guideline for Crowdsourced Software Engineering Activities, $\mathrm{PhD}$ Thesis; Universiti Tenaga Nasional, 2019.

[12] W.-T. Tsai, W. Wu, and M. N. Huhns, "Cloud-based software crowdsourcing", IEEE Internet Computing, 18(3), 78-83, 2014.

[13] M. Hosseini, K. Phalp, J. Taylor,and R. Ali, "The four pillars of crowdsourcing: A reference model", 2014 IEEE Eighth International Conference on the Research Challenges in Information Science (RCIS), 2014.
[14] Daniel, P. Kucherbaev, C. Cappiello, B. Benatallah,and M. Allahbakhsh, "Quality control in crowdsourcing: A survey of quality attributes, assessment techniques, and assurance actions",ACM Computing Surveys (CSUR), 51(1), 7, 2018.

[15] J. de Beer, I. P. McCarthy, A. Soliman, and E. Treen,"Click here to agree: Managing intellectual property when crowdsourcing solutions", Business Horizons, 60(2), 207-217,2017.

[16] Ghezzi, D. Gabelloni, A. Martini,andA. Natalicchio, "Crowdsourcing: a review and suggestions for future research". International Journal of Management Reviews, 20(2), 343-363, 2018.

[17] Sar1, A. Tosun, and G. I. Alptekin, "A systematic literature review on crowdsourcing in software engineering", Journal of Systems and Software, 153, 200-219, 2019.

[18]R. Vinaja,"Software Sourcing in the Age of Open: Leveraging the Unknown Workforce",Journal of Global Information Technology Management, 19(1), 73, 2016.

[19]R. C. Ford, B. Richard, and M. P. Ciuchta, "Crowdsourcing: A new way of employing nonemployees?”, Business Horizons, 58(4), 377-388, 2015.

[20] Sharp, "Creativity and Collaboration in Software Design and Development",Proceedings of the European Conference on Cognitive Ergonomics, 2016.

[21] L. Liu, L. Feng, Y. Li, D. Jing, and H. Yang, "Flourishing creativity in software development via Internetware paradigm", Science China Information Sciences, 59(8), 080103, 2016.

[22] D. Suh, and D.-h. Oh, "The role of software intellectual property rights in strengthening industry performance: Evidence from South Korea", Technological Forecasting and Social Change, 92, 140-154, 2015.

[23] Afegbua, "Understanding intellectual property rights in software engineering!", Consolex Legal Practitioners, 2017.

[24] K. B. C. Saxena, S. J. Deodhar, and M. Ruohonen, "Intellectual Property Management in Software Business", Business Model Innovation in Software Product Industry, pp. 109-127: Springer, 2017.

[25] Vanmellea. Guideline for treatment of intellectual property right in information and communication technology contracts, NewZealand Government, Retrieved from https://www.ict.govt.nz/assets/Uploads/Documents/iprguidelines-2008.pdf, 2008.

[26] Australia Government Intellectual Property Policy and Best Practice Guidelines, Retrieved from https://www.commerce.wa.gov.au/sites/default/files/ato ms/files/wa_govt_ip_policy_and_best_practice_guidelin es.pdf, 2003.

[27] Choleswo. Intellectual property guideline for custom software development contracts, Canada Government, Retrieved

from http://www.hpw.gov.yk.ca/pdf/intellectual_property_gui delline.pdf. 2005.

[28] Ministry of Industry, Implementation guide policy on title to intellectual property arising under crown 
Badariah Solemon et al., International Journal of Emerging Trends in Engineering Research, 8(10), October 2020, 6675 - 6683

procurement contracts, CanadaGovernment, Retrieved from

https://www.ic.gc.ca/eic/site/068.nsf/eng/00005.html, 2015.

[29]R. Bekkers, and A. Updegrove, "IPR policies and practices of a representative group of standards-setting organizations worldwide"., Commissioned by the Committee on Intellectual Property Management in Standard-Setting Processes, National Research Council, Washington, 2013.

[30] R. Buckworth, R. Bustamante, M. Haywood, G. Fry, M. Tonks, W. Venables \&M. Barwick, Ownership of Intellectual property rights, 2015.

[31] R. L. Parr, Intellectual property: valuation, exploitation, and infringement damages, John Wiley \& Sons, 2018.

[32]D. Mosey, "Early contractor involvement in building procurement: contracts, partnering and project management", John Wiley \& Sons, 2009.

[33] Othman, "Intellectual Property Commercialization in the EU: Policy Options and Practical Instruments", Researchgate.com, 2018.

[34]K. Burden, "The voice of reason... finding middle ground in IT contracts", Computer Law \& Security Review, 20(3), 204-205, 2004.

[35]R. Manzini, and V. Lazzarotti, Intellectual property protection mechanisms in collaborative new product development, 2016.

[36] M. M. Rajaeian, A. Cater-Steel, and M. Lane, IT outsourcing decision factors in research and practice: a case study. arXiv preprint arXiv:1606.01454, 2016.

[37]B. Powers, Automated clickwrap and browsewrap system: Google Patents, 2015.

[38] Canino, "The Electronic Sign-in-Wrap Contract: Issues of Notice and Assent, the Average Internet User Standard, and Unconscionability", UCDL Rev., 50, 535, 2016.

[39] S. W. Tu, J. Campbell, and M. A. Musen, "The structure of guideline recommendations: a synthesis". Annual Symposium Proceedings the AMIA, 2013.

[40] Marotta-Wurgler, Will Increased Disclosure HelpEvaluating the Recommendations of the ALI's Principles of the Law of Software Contracts", U. Chi. L. Rev., 78, $165,2011$.

[41] Hussain, A., Mkpojiogu, E.O.C., Kamal, F.M. (2016). Mobile video streaming applications: A systematic review of test metrics in usability evaluation. Journal of Telecommunication, Electronic and Computer Engineering, 8 (10), pp. 35-39.

[42] M. Peleg, S. Tu, J. Bury, P. Ciccarese, J. Fox, R. A. Greenes, and A. Kumar, "Comparing computerinterpretable guideline models: a case-study approach". Journal of the American Medical Informatics Association, 10(1), 52-68, 2003.

[43] Dr.S.V. Manikanthan, Dr.T. Padmapriya. "Network Lifetime Maximization in WSN based on Enhanced Clustering Techniques". JARDCS, Vol. 29 No. 6s, 2020. 